\title{
Optical detection of $\mathrm{Cu}^{2+}$ ion using a SQ-dye containing polymeric thin-film on Au surface
}

\author{
Kyungsik Ock ${ }^{\mathrm{a}}$, Gabsoo Jang ${ }^{\mathrm{a}}$, Yongrae $\mathrm{Roh}^{\mathrm{b}}$, Sunghoon Kimc, Jaeho \\ $\mathrm{Kim}^{\mathrm{d}}$, Kwangnak Koh ${ }^{\mathrm{e}, *}$ \\ ${ }^{a}$ Department of Sensor Engineering, Graduate school, Kyungpook National University, Taegu 702-701, South Korea \\ ${ }^{\mathrm{b}}$ School of Mechanical Engineering, Kyungpook National University, Taegu 702-701, South Korea \\ ${ }^{\mathrm{c}}$ Department of Dyeing and Finishing, Kyungpook National University, Taegu 702-701, South Korea \\ ${ }^{\mathrm{d}}$ Department of Molecular Science and Technology, Ajou University, Suwon 442-749, South Korea \\ ${ }^{\mathrm{e}}$ Department of Chemical Engineering, Kyungpook National University, Taegu 702-701, South Korea
}

Accepted 10 August 2001

\begin{abstract}
In this study, we have fabricated $\mathrm{Cu}^{2+}$ ion sensor using a squarylium dye (SQ-dye) containing polymeric thin-film. Surface Plasmon Resonance (SPR) was used as a signal amplifier to achieve high sensitivity and large linear dynamic range for detection of $\mathrm{Cu}^{2+}$ ion. High selectivity to $\mathrm{Cu}^{2+}$ ion was obtained by the effective electro-static interaction between SQ-dye and $\mathrm{Cu}^{2+}$ ion in the polymeric film. The optimal analytical condition of high selectivity and sensitivity in the wider linear dynamic range obtained in this study may be a result of the cooperative 'hard-soft' metal ion-ligand interaction and effective detection of refractive index changes by the complexation of $\mathrm{Cu}^{2+}$ ion and SQ-dye in SPR measurement. Among 10 different alkali metal, alkaline earth metal, and transition metal ions, SQ-dye in poly(vinylchloride)-poly(vinyl acetate)-poly(vinyl alcohol) (PVC-PVAc-PVA) copolymer film showed the highest selectivity to $\mathrm{Cu}^{2+}$ ion. Although the interaction between SQ-dye and metal ions has not been well understood, both cooperative 'hard-soft' metal ion-ligand interaction and size-selective recognition of $\mathrm{Cu}^{2+}$ ion to SQ-dye may contribute to high selectivity. Furthermore, additional sensitivity in the detection of $\mathrm{Cu}^{2+}$ ion by SPR was obtained by matching the wavelength of probing radiation of SPR and absorption maximum of SQ-dye at 675 $\mathrm{nm}$, which allow to detect small changes in the refractive index by complex formation on the sensing surface. This result may apply in development of the $\mathrm{Cu}^{2+}$ ion selective sensor for medical, biochemical, and environmental applications. (c) 2001 Elsevier Science B.V. All rights reserved.
\end{abstract}

Keywords: Surface plasmon resonance; Hard-soft metal ion interaction; Squarylium dye; Refractive index change

\footnotetext{
* Corresponding author. Tel.: + 82-53-950-6838; fax: + 82-53-950-6615.
}

E-mail address: knkoh@knu.ac.kr (K. Koh). 


\section{Introduction}

The soil and water pollution by the mass quantity of industrial waste which has been caused by rapid industrial development and growth of population, have become one of the main social problems. Especially, the pollution by harmful heavy metal ions discharged from the factories is the most serious one [1,2]. It is well known that many heavy metal ions among the pollutants are not decomposed and accumulates continuously and finally it is impossible to be extracted out fully. Furthermore, the metal ion absorbed into a body not only reduces the body metabolism but also causes harmful effect when the ion is accumulated over certain level. Copper, among various heavy metals, is an important element in many industrial processes and is an essential inorganic substance for a human body. If it is overtaken, however, it damages liver cells, causes various diseases and obstructs growth of many crops $[3,4]$.

From the viewpoint of these backgrounds, we have paid attention to a new approach in order to obtain more selective and sensitive detection of $\mathrm{Cu}^{2+}$ ion in solution than conventional methods [5-7]. According to the previous our UV-Visible spectroscopic study on the SQ-dye, the ion sensing thick film containing SQ-dye on a glass plate (optode) showed that the maximum absorption peak at $640 \mathrm{~nm}$ was decreased with increasing the concentration of $\mathrm{Cu}^{2+}$ ion. On the other hand, the absorption changes by the other co-exist metal ions were not detectable [7]. Thus, naturally these preliminary results on the superior characteristics of SQ-dye require the effort to combine with the promising optical technique that can maximize the $\mathrm{Cu}^{2+}$ ion sensing property of SQ-dye.

In this study, we used the SPR method as the suitable optical technique, which can effectively monitor the interaction between SQ-dye and $\mathrm{Cu}^{2+}$ ion. SPR technique is well-known signal transducing principle that can convert the chemical signal is caused by the interaction between the analyte and recognition material to the useful optical signal [8]. Its optical signal may appear as the refractive index change and/or the thickness change [9]. In the case of the polymeric ion sensing film, the refractive index change can be domi- nant optical signal. Especially, the polymeric film containing a dye that absorbs the light in the visible range can produce more improved refractive index changes as a result of sensing mechanism. It can be explained easily by the anomalous dispersion near the absorption maximum [9-11].

\section{Materials and methods}

\subsection{Preparation of squarylium dye 4 (SQ-dye)}

Compound 4 (SQ-dye) was synthesized according to previously reported method as follows (Fig. 1) [12]. 2,3,3-Trimethylindolenine 1 (1.2 g, 7.54 mmol) and methyl iodide $(1.07 \mathrm{~g}, 7.54 \mathrm{mmol})$ were refluxed for $7 \mathrm{~h}$ in $70 \mathrm{ml}$ of acetonitrile. After reaction, 1,2,3,3-tetramethylindolenium iodide 2 was obtained in $67.8 \%$ yield $(1.54 \mathrm{~g})$ by filtration. Then, squaric acid $3(0.68 \mathrm{~g}, 6 \mathrm{mmol})$ and the methylene base 2 ( $3.61 \mathrm{~g}, 12 \mathrm{mmol}$ ) were refluxed for $3 \mathrm{~h}$ in a mixture of $60 \mathrm{ml}$ of $n$-butanol/benzene $(4: 1, v / v)$ containing $3 \mathrm{ml}$ of quinoline. Water was removed azeotropically using a Dean-Stark trap. The reaction mixture was cooled to room temperature. The precipitated crude product were separated by filtration and washed with $n$-hexane (yield: $61 \%$ ).

\subsection{Sensing membrane}

The casting solution to make polymeric sensing thin-film on $\mathrm{Au}$ surface was composed of PVC-PVAc-PVA copolymer (Aldrich Chemical Co., M.W. $=27000,14.96$ wet wt.\%), plasticizer (Dioctylphtalate, Aldrich Chemical Co., 65.30 wet wt.\%), anionic site [potassium tetrakis (4-chlorophenylborate), Fluka, 6.32 wet wt.\%], SQ-dye (13.42 w/w \%) and THF (Tetrahydrofuran, Junsei Chemical Co.) as a solvent. This solution mixture was spin-coated on the surface of $\mathrm{Au}$ layer (membrane thickness: approx. $12 \mathrm{~nm}, \mathrm{Au}$ thickness: $50 \mathrm{~nm}, \mathrm{Ni}-\mathrm{Cr}$ thickness: approx. $3 \mathrm{~nm}$ ). A microscope cover glass is used for the substrate of sensor chip. Gold surface (thickness, $50 \mathrm{~nm}$ ) was deposited by electron-beam evaporation after approximately $3 \mathrm{~nm}$ thickness of nickel-chromium 
<smiles>CC1=Nc2ccccc2C1(C)C</smiles>

1<smiles>C=[R14](C)C</smiles>

$\mathrm{CH}_{3} \mathrm{CN}$, Reflux<smiles>CC1=[N+](C)c2ccccc2C1(C)C</smiles>

2<smiles>O=c1c(O)c(O)c1=O</smiles><smiles>CN1C(=CC2C([O])C(C=C3C(C)(C)c4ccccc4C3(C)C)C2[O-])C(C)(C)c2ccccc21</smiles>

Squarylium dye (SQ-dye)

Fig. 1. Synthetic route of SQ-dye.

as an adhesion layer formed onto the surface of cover glass. (Fig. 2).

\subsection{SPR measurement system}

The homemade SPR system was based on the traditional Kretschmann configuration (Fig. 3) [13]. The p-polarized laser beam $(4.5 \mathrm{~mW}, \lambda=675$ $\mathrm{nm})$ through the prism was reflected and detected by optical power meter (ANDO electric Co. Ltd., AQ1135E). A motorized rotary stage with a stepping motor in order to change the incident angle of the laser beam rotated the prism holder having the prism on a sensor chip. The stepping motor was controlled by a stage controller with a $0.004^{\circ}$ of minimum resolution. The sample flow cell was placed beneath the sensor chip. Each sample solution was flowed into the sample cell from low concentration to high one by pumping.

\subsection{Preparation of sample solutions}

Metal ions $\left(\mathrm{Cu}^{2+}, \mathrm{Ag}^{+}, \mathrm{K}^{+}, \mathrm{Na}^{+}, \mathrm{Zn}^{2+}, \mathrm{Mg}^{2+}\right.$, $\mathrm{Ca}^{2+}, \mathrm{Co}^{2+}, \mathrm{Li}^{+}, \mathrm{Cd}^{2+}, \mathrm{Hg}^{2+}=1.0 \times 10^{-12}-1.0 \times$

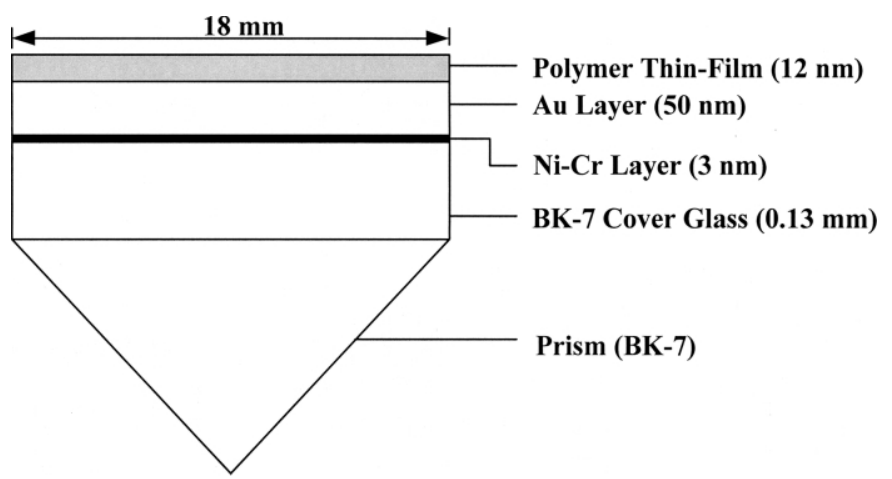

Fig. 2. A cross-sectional view of a sensor chip for $\mathrm{Cu}^{2+}$ ion sensing. 


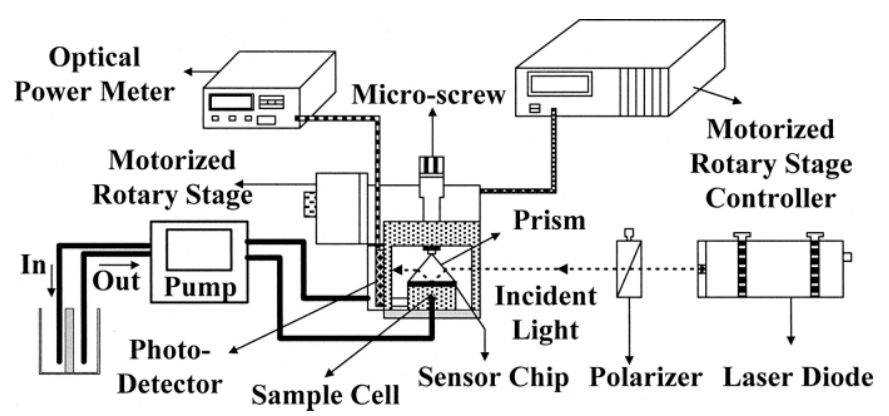

Fig. 3. Schematic diagram of a SPR sensor system.

$10^{-4} \mathrm{M}$, except $\mathrm{Pb}^{2+}=1.0 \times 10^{-12}-1.0 \times 10^{-5} \mathrm{M}$, because this ion precipitates at above $>10^{-5} \mathrm{M}$ ) were dissolved in $\mathrm{pH} 7.0,0.05 \mathrm{M}$ Tris $-\mathrm{H}_{2} \mathrm{SO}_{4}$ buffer solution to make various concentrations sample solutions. Tris- $\mathrm{H}_{2} \mathrm{SO}_{4}$ buffer solution was used as a reference solution (background). All counter anions of metal ions are nitrate. $\mathrm{Cu}^{2+}$ ion selective behavior of the SQ-dye to the other interfering ion was investigated by means of Separate Solution Method (SSM) that determines separate calibration plots for the $\mathrm{Cu}^{2+}$ ion and the interfering ion at constant condition [14].

\section{Results and discussion}

As expected above, $\mathrm{Cu}^{2+}$ ion molecular sensing system using SQ-dye showed excellent selectivity

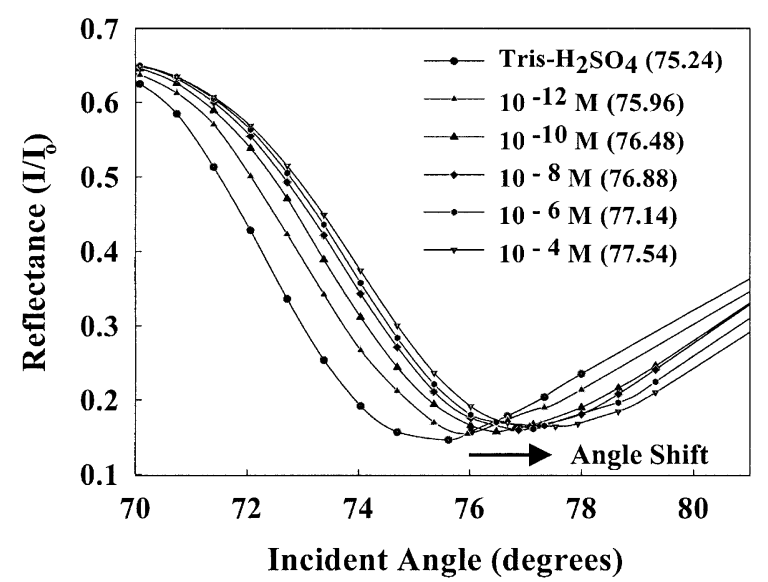

Fig. 4. Resonance angle shifts according to various $\mathrm{Cu}^{2+}$ ion concentrations. and remarkable sensitivity with wide ion concentration detection ranging from $1.0 \times 10^{-12} \mathrm{M}$ to $1.0 \times 10^{-4} \mathrm{M}$ linearly. Even though the reproducible results highly depend on the film deposition conditions, especially on the sensing film thickness, if the thickness could preserve constantly at each measurement, these selectivity and sensitivity were guaranteed reproducibly.

Fig. 4 indicates typical SPR curves related to the sample solutions with different $\mathrm{Cu}^{2+}$ ion concentrations. The resonance angle difference between Tris $-\mathrm{H}_{2} \mathrm{SO}_{4}$ buffer solution (as a reference) and the highest concentration of $\mathrm{Cu}^{2+}$ ion $\left(1.0 \times 10^{-4} \mathrm{M}\right)$ was $2.30^{\circ}$ in our SPR sensing system.

Moreover, even at the lowest $\mathrm{Cu}^{2+}$ ion concentration, $1.0 \times 10^{-12} \mathrm{M}$, the resonance angle was significantly changed to $0.70^{\circ}$. This is distinguishable value in comparison with angle shifts of the other metal ions at high concentration which stay at approximately $0.50^{\circ}$. These results describe that the good selectivity and sensitivity of the SQ-dye sensing to the $\mathrm{Cu}^{2+}$ ion in the polymeric thin-film can be obtained through the SPR sensing method, although the SQ-dye system used as a molecular sensing interface is not so well designed molecule for the selective $\mathrm{Cu}^{2+}$ ion sensing. It is considered that both cooperative 'hard-soft' metal ion-ligand interaction and size-selective recognition of $\mathrm{Cu}^{2+}$ ion to SQ-dye may contribute to high selectivity [15]. Furthermore, the signal related to the effective electro-static interaction between SQ-dye and $\mathrm{Cu}^{2+}$ ion may be amplified through the SPR sensing system with high sensitivity in the wider linear dynamic range (Fig. 5). 


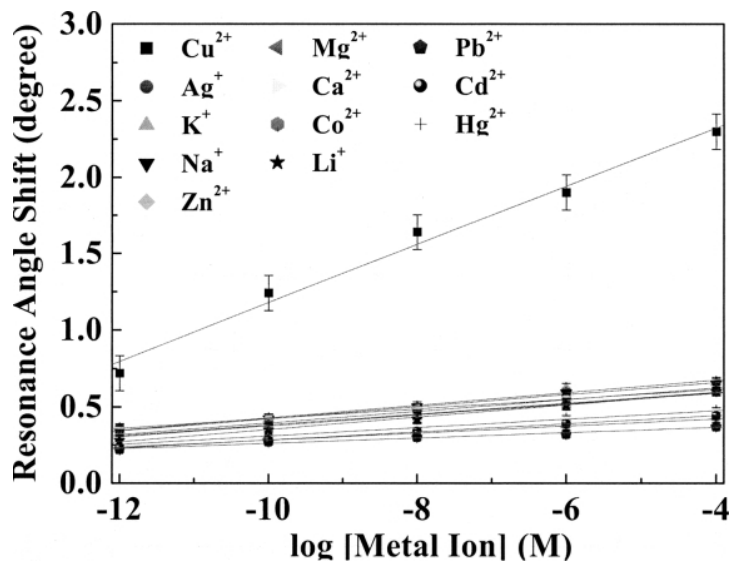

Fig. 5. Resonance angle shifts according to different concentrations of several metal ions.

As described previously, the light absorption property of SQ-dye can be regarded as very important factor to construct the highly sensitive $\mathrm{Cu}^{2+}$ ion sensor using SPR method. Because the SQ-dye has the maximum absorption peak at 640 $\mathrm{nm}$, the $\mathrm{Cu}^{2+}$ ion sensing polymeric film containing the SQ-dye have the highest refractive index at the wavelength of laser diode $(675 \mathrm{~nm})$ according to the anomalous dispersion relation [9-11]. So that the variation of absorbance near $675 \mathrm{~nm}$ by the increase of ion concentration can give rise to change the refractive index of ion sensing film greatly. This can strongly affect the SPR phenomenon such as the reflectance variation, resonance angle shift, and so on. Consequently it can offer more sensitive $\mathrm{Cu}^{2+}$ ion detection mechanism related to the improved resonance angle shifts. More details of physical analysis on these interesting light absorption related with SPR are under studying.

In conclusion, from the results above, the possibility of constructing more accurate $\mathrm{Cu}^{2+}$ ion sensor system was established. The highly selective detection to the $\mathrm{Cu}^{2+}$ ion was achieved by the SQ-dye molecular system that produces the effective electro-static interaction between SQdye and $\mathrm{Cu}^{2+}$ ion. When combining this molecular sensing system with the SPR method, the sensitivity of $\mathrm{Cu}^{2+}$ ion detection was maximized.
The maximum resonance angle shifts was $2.30^{\circ}$ at $1.0 \times 10^{-4} \mathrm{M} \mathrm{Cu}^{2+}$ ion concentration. The dynamic detection range of this chemical sensor was wide from $1.0 \times 10^{-12} \mathrm{M}$ to $1.0 \times 10^{-4} \mathrm{M}$. Furthermore, the absorption property of the SQ-dye can improve the sensitivity to the $\mathrm{Cu}^{2+}$ ion detection. It can be maximized through matching the wavelength of probing radiation of SPR $(675 \mathrm{~nm})$ with near the absorption maximum of SQ-dye, exactly the shoulder of the absorption maximum. Thus, this $\mathrm{Cu}^{2+}$ ion sensor may be useful in the several medical, biomedical and environmental inspection.

\section{Acknowledgements}

This work was supported by grant No. 2000-230800-001-3 from the Basic Research Program of the Korea Science \& Engineering Foundation.

\section{References}

[1] P.A. Brown, S.A. Gill, S.J. Allen, Water Res. 34 (2000) 3907-3916.

[2] Q. Gan, Waste Manage. 20 (2000) 695-701.

[3] Y. Song, M. Chen, Clin. Biochem. 33 (2000) 589-590.

[4] L.A. Brun, J. Maillet, P. Hinsinger, M. Pépin, Environ. Pollut. 111 (2001) 293-302.

[5] M.C. Cleij, P. Scrimin, P. Tecilla, U. Tonellato, J. Org. Chem. 62 (1997) 5592-5599.

[6] B.L. Seleznev, A.V. Legin, Y.G. Vlasov, J. Anal. Chem. 51 (1996) 882-887.

[7] S.H. Kim, S.K. Han, S.H. Park, S.M. Lee, S.M. Lee, K.N. Koh, S.W. Kang, Dyes Pigm. 41 (1999) 221-226.

[8] J. Homola, S.S. Yee, G. Gauglitz, Sensors Actuators B 54 (1999) 3-15.

[9] A. Hanning, J. Roeraade, J.J. Delrow, R.C. Jorgenson, Sensors Actuators B 54 (1999) 25-36.

[10] I. Pockrand, J.D. Swalen, R. Santo, A. Brillant, M.R. Philpott, J. Chem. Phys. 69 (1978) 4001-4011.

[11] S. Boussaad, J. Pean, N.J. Tao, Anal. Chem. 72 (2000) 222-226.

[12] S.H. Kim, S.H. Hwang, Dyes Pigm. 36 (1998) 139-148.

[13] E. Kretschmann, Z. Phys. 241 (1971) 313-324.

[14] K. Seiler, Ion-Selective Optode Membranes, Fluka, Buchs, 1993, p. 33,.

[15] K.N. Koh, T. Imada, T. Nagasaki, S. Shinkai, Tetrahedron Lett. 35 (1994) 4157-4160. 